Mikhaylovskaya Z. A. a,b, Buyanova E.S. ${ }^{\text {a }, \text { Smirnov D. Yu. }}$

${ }^{a}$ Ural Federal University,

19 Mira st., Ekaterinburg, 620002, Russia

${ }^{b}$ Zavaritsky Institute of Geology and Geochemistry,

Ural Branch of the Russian Academy of Sciences,

15 A. Vonsovskogo st., Ekaterinburg, 620016, Russia e-mail:zozoikina@mail.ru

\title{
Determination of $\mathrm{Bi}$ in complex oxide samples by atomic absorption spectrometry by using ordinary acetylene - air flame atomization
}

In the present work the air/acetylene flame atomic absorption spectrometry was used for bismuth determination in complex oxides. Interference studies were carried out, and interference with vanadium and molybdenum was detected. The method of standard additions and traditional calibration curve method were used. Calibration and standard addition curves were fitted with linear and polynomial functions. It was shown that using polynomial function gives better results for the standard additions method for determination of bismuth by acetylene/air flame atomic absorption spectrometry. The calibration curve method was shown to be correct at low $(<10 \mathrm{mg} / \mathrm{L})$ concentration of an interferent.

Keywords: determination of bismuth; flame atomic absorption spectrometry; analysis of solid oxides.

Received: 09.12.2019. Accepted: 27.12.2019. Published: 30.12.2019.

(C) Mikhaylovskaya Z. A., Buyanova E. S., Smirnov D. Yu., 2019

\section{Introduction}

Bismuth-containing complex oxides show excellent ionic-conductive, ferroelectric, catalytic and photocatalytic properties [1-5]. They also exhibit piezoelectric, electro-optic, elasto-optic, photoconductive and multiferroic characteristics [6-8]. At the same time, bismuth oxidebased compounds are relatively cheap and, therefore, they have a lot of potential applications. Traditional method of synthesis of the Bi-containing complex oxides is conventional solid-state technology, when stoichiometric amounts of precursors are mixed and heated at $500-1000^{\circ} \mathrm{C}$ for a few dozens of hours. If this process is carried out in open crucibles or initial temperatures of annealing are too high, then partial evaporation of bismuth can take place. As a result, a changing of composition and of main properties of complex oxide can be observed. And that is why solid oxide composition is ordinarily controlled by various types of spectral or chemical analyses.

The samples of Bi-containing complex oxides have several features. Firstly, they often include three, four or more metals, which can lead to aliasing errors or problems of sample separation. Secondly, the concentration of $\mathrm{Bi}$ is relatively high and no concentrating techniques are need- 
ed. And thirdly, numerous methods require dissolution of the samples in concentrated mineral acids, which can influence the analytical signal. Analytical techniques of determination of low concentrations of $\mathrm{Bi}$ in solid matrices were described earlier [9]. A variety of analytical techniques of Bi determination includes spectrophotometric [10-11], electro analytical methods [12], solid phase extraction [13] and cloud point extraction [14] methods. All of these methods are quite sensitive, but all of them require separating the sample from other metals and concentrating of bismuth.

Atomic absorption spectrometry (AAS) is also widely used for determination of $\mathrm{Bi}$ [13, 15-17]. Although electrothermal AAS (ETAAS) and inductively-coupled plasma mass spectrometry offer high sensitivity, the costs related to the instrument and the consumables are relatively high [17]. Hydride generation coupled with AAS (HG-AAS) is also a very well established sensitive technique for Bi determination [16], but it also necessitates expensive equipment.

Flame AAS (FAAS) can be used as an alternative technique for determination of Bi. In many laboratories, FAAS is still commonly used as a preferred technique for its simplicity and low-cost operation. Using of additional oxidizer (for example, $\mathrm{N}_{2} \mathrm{O}$ ) or atom traps (for example, slotted quartz tube on top of the flame atomizer) leads to the increase in sensitivity of FAAS [17]. Equipment manufacturers do not recommend FAAS for Bi determination in the case of using only compressed air as oxidizer, because relatively low temperature of flame results in high detection threshold of Bi concentration [18]. However, for the samples with relatively high Bi concentration, the spectrophotometric [11] and electroanalytical methods [12] have been traditionally used. As a result, guidelines on using FAAS for the $\mathrm{Bi}$ determination with compressed air as the only oxidizer are virtually nonexistent. The analysis of Bi-containing complex oxides by spectrophotometric and electroanalytical methods requires complex sample preparation and separation of Bi from another elements and mineral acids. These operations can be partially ignored if using any kind of FAAS, but crucial information on the optimal measurement conditions and effects of the presence of different metal ions has not been reported yet.

In the present work, the air/acetylene flame AAS was used for Bi determination in complex oxides. The interference studies on how different metal ions $\left(\mathrm{Na}^{+}, \mathrm{K}^{+}\right.$, $\mathrm{Mg}^{2+}, \mathrm{Ca}^{2+}, \mathrm{Sr}^{2+}, \mathrm{Ba}^{2+}, \mathrm{Fe}^{3+}, \mathrm{Co}^{2+}, \mathrm{Mn}^{2+}$, $\mathrm{Ni}^{2+}, \mathrm{Pb}^{2+}, \mathrm{La}^{3+}, \mathrm{Mo}^{6+}, \mathrm{V}^{5+}$ ) and mineral acids influence the analytical signal of $\mathrm{Bi}$ were performed. The different instrumental conditions were optimized. As a result, a series of recommendations for determination of Bi by air/acetylene FAAS was provided.

\section{Experimental}

Bismuth standard solution, $500 \mathrm{mg} / \mathrm{L}$, was prepared by dissolution of calcined at $650{ }^{\circ} \mathrm{C} \mathrm{Bi}_{2} \mathrm{O}_{3}$ in stoichiometric amount of nitric acid. Standards with lower concentrations $(10-100 \mathrm{mg} / \mathrm{L})$ used for calibration were prepared from stock solutions by appropriate dilutions with bidistilled

water. For studies of influence of concentrated acids, high-purity acids $\left(\mathrm{HCl}, \mathrm{H}_{2} \mathrm{SO}_{4}\right.$, $\mathrm{HNO}_{3}$ ) with concentrations of $0-6 \mathrm{~mol} / \mathrm{L}$ were used.

For the interference studies, interferent/analyte (mass/mass) ratio was kept at 0.25 to $5.00 . \mathrm{Na}^{+}, \mathrm{K}^{+}, \mathrm{Mg}^{2+}, \mathrm{Ca}^{2+}, \mathrm{Sr}^{2+}$, 
$\mathrm{Ba}^{2+}, \mathrm{Fe}^{3+}, \mathrm{Co}^{2+}, \mathrm{Mn}^{2+}, \mathrm{Ni}^{2+}, \mathrm{Pb}^{2+}, \mathrm{La}^{3+}$, $\mathrm{Mo}^{6+}, \mathrm{V}^{5+}$ solutions were prepared from their $1000 \mathrm{mg} / \mathrm{L}$ stock solution. Stock solutions were prepared from $\mathrm{NaNO}_{3}$, $\mathrm{K}_{2} \mathrm{CO}_{3}, \mathrm{MgCO}_{3}, \mathrm{CaCO}_{3}, \mathrm{SrCO}_{3}, \mathrm{Ba}-$ $\mathrm{CO}_{3}, \mathrm{Fe}\left(\mathrm{NO}_{3}\right)_{3} \cdot 9 \mathrm{H}_{2} \mathrm{O}, \mathrm{Co}\left(\mathrm{NO}_{3}\right)_{2} \cdot 6 \mathrm{H}_{2} \mathrm{O}$, $\mathrm{Mn}\left(\mathrm{NO}_{3}\right)_{2} \cdot 4 \mathrm{H}_{2} \mathrm{O}, \mathrm{Ni}\left(\mathrm{NO}_{3}\right)_{2} \cdot 6 \mathrm{H}_{2} \mathrm{O}, \mathrm{PbO}$, $\mathrm{La}_{2} \mathrm{O}_{3},\left(\mathrm{NH}_{4}\right)_{6} \mathrm{Mo}_{7} \mathrm{O}_{24} \cdot 4 \mathrm{H}_{2} \mathrm{O}, \mathrm{NH}_{4} \mathrm{VO}_{3}$, respectively. All reagents were of analytical grade.

Solaar 6M (Thermo Scientific) atomic absorption spectrometer equipped with a deuterium $\left(\mathrm{D}_{2}\right)$ background correction system was used for Bi determination. Air-acetylene type flame was used with a burner head of $750 \mathrm{~mm}$. Thermo Scientific brand Bi hollow cathode lamp with an operating current of $9.0 \mathrm{~mA}$ was used as a radiation source, at the wavelength of $223.1 \mathrm{~nm}$ and with the spectral band pass of $0.5 \mathrm{~nm}$. The type of the analytical signal (average, maximum), measuring time, burner position and gas consumption were optimized during experiments. For the interference characterization, the $\mathrm{Ab}$ sorbance (A) and Relative Absorbance De-

\section{Results and discussion}

\section{Interference studies}

The concentrated acids are often used for dissolution of Bi-rich containing ceramic samples. Besides, in aqueous samples, some acid is required to avoid hydrolysis and precipitation of bismuth compounds. To study the effect of acids on the analytical signal of atomic absorption of bismuth, three series of standard solutions were tested, with each sample containing $20 \mathrm{mg} / \mathrm{L}$ of bismuth and $\mathrm{HCl}, \mathrm{H}_{2} \mathrm{SO}_{4}$ or $\mathrm{HNO}_{3}$ with a concentration in the range from 0.5 to $6 \mathrm{~mol} / \mathrm{L}$. It was found that presence of $\mathrm{HCl}$ or $\mathrm{HNO}_{3}$ with the concentration of $0.7 \mathrm{~mol} / \mathrm{L}$ and more leads to the decrease in absorbance. Namely, crease (RAD) were used. RAD was calculated according to the following equation:

$$
\Delta A=\frac{\left(A_{0}-A_{i}\right)}{A_{0}} \cdot 100 \% \text {, }
$$

where $A_{0}$ is the Absorbance without any interferent and $A_{i}-$ is the Absorbance with an interferent.

The methods of standard additions and traditional calibration curve method were used. Calibration and standard addition curves were fitted using linear function and polynomial function in OriginLab software.

The typical Bi-rich complex oxide samples for analysis $\left(\mathrm{Bi}_{4} \mathrm{~V}_{1.5} \mathrm{Cr}_{0.4} \mathrm{Fe}_{0.1} \mathrm{O}_{11}\right.$, $\mathrm{Bi}_{12.7} \mathrm{Mn}_{0.3} \mathrm{Mo}_{4.6} \mathrm{P}_{0.5} \mathrm{O}_{34}, \mathrm{Bi}_{1.9} \mathrm{Ba}_{0.1} \mathrm{MoO}_{6}$, $\mathrm{Bi}_{4} \mathrm{~V}_{0.4} \mathrm{Ta}_{1.6} \mathrm{O}_{11}$ ) were synthesized by conventional solid-state technology from initial oxides, carbonates and ammonia phosphate. 50-70 mg of each of the solid oxide was dissolved in $20 \mathrm{~mL}$ of hot $\mathrm{HNO}_{3}(35 \%)$ (for molybdates) or in $10 \mathrm{~mL} \mathrm{HCl}$ (35\%) (for vanadates). Solutions for analysis were prepared from stock solutions by appropriate dilutions.

$\operatorname{RAD}(\triangle A)$ is about $1 \%$ and more than $1.5 \%$ when the concentration of acids is about $0.7 \mathrm{~mol} / \mathrm{L}$ and more than $2.5 \mathrm{~mol} / \mathrm{L}$, respectively (see Fig. 1). Similarly, $\mathrm{H}_{2} \mathrm{SO}_{4}$ with the concentration of $0.7 \mathrm{~mol} / \mathrm{L}$ leads to the RAD of about $2.5 \%$. The further increase of sulphuric acid concentration results in a dramatic decrease of absorbance signal (see Fig. 2). Thus, using $\mathrm{H}_{2} \mathrm{SO}_{4}$ with $5.4 \mathrm{~mol} / \mathrm{L}$ concentration leads to the reduction in absorbance by half. Probably, it is due to the flame temperature reduction and the formation of stable molecular fragments. That is why the use of sulphuric acid is strongly discouraged for Bi-containing ceramic dissolution, but if it cannot be 
avoided, the matrix effect must be taken into account.

Bi-containing complex oxide materials can also include several other metals, such as alkali metals, alkaline earth metals, transition metals and some rare-earth metals. In the present work, it was shown that $\mathrm{Na}, \mathrm{K}, \mathrm{Mg}, \mathrm{Ca}, \mathrm{Sr}, \mathrm{Ba}, \mathrm{Fe}, \mathrm{Co}, \mathrm{Mn}, \mathrm{Ni}, \mathrm{La}$, and $\mathrm{Pb}$ do not affect the absorbance by bismuth $(20 \mathrm{mg} / \mathrm{L}$ concentration) if the interferent/analyte (mass/mass) ratio is kept at 0.25 to 5.00 (see Fig. 3). RAD is less than $2 \%$ in the range of interferent concentrations from 5 to $100 \mathrm{mg} / \mathrm{L}$. In the case of $\mathrm{V}$ and Mo, the strong matrix effect is observed: as seen in Fig. 4, RAD is $10-100 \%$.

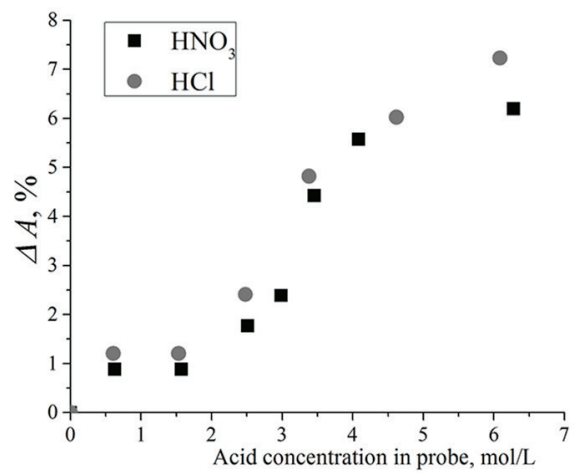

Fig. 1. RAD as a result of interference between bismuth and $\mathrm{HCl}$ or $\mathrm{HNO}_{3}$ acid

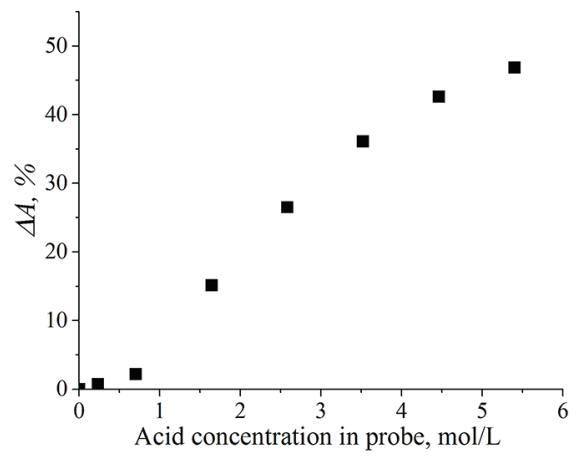

Fig. 2. $\mathrm{RAD}$ as a result of interference between bismuth and $\mathrm{H}_{2} \mathrm{SO}_{4}$ acid
It can be caused by stabilization of anionic forms of $\mathrm{V}$ and Mo ions, such as $\mathrm{VO}_{4}^{3-}$ and $\mathrm{MoO}_{4}^{2-}$. As a result, insoluble molybdates and vanadates of bismuth are formed. The precipitates produced consist of colloidal particles; therefore, the turbidity of the solution is not observed, and only a slight colour change can be noticed. The formation of insoluble molybdates and vanadates of bismuth can be avoided by addition of acid, which promotes the destruction of mentioned compounds. For example, the following reactions are possible:

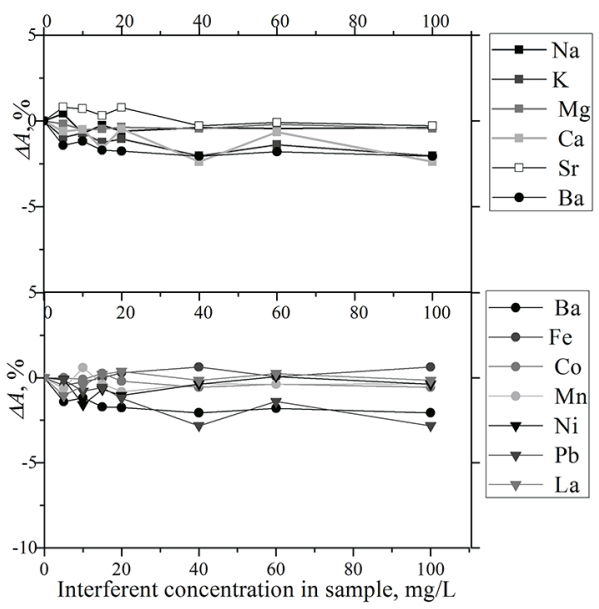

Fig. 3. RAD as a result of interference between bismuth and $\mathrm{Na}, \mathrm{K}, \mathrm{Mg}, \mathrm{Ca}, \mathrm{Sr}, \mathrm{Ba}$, $\mathrm{Fe}, \mathrm{Co}, \mathrm{Mn}, \mathrm{Ni}, \mathrm{La}, \mathrm{V}, \mathrm{Mo}$ or $\mathrm{Pb}$

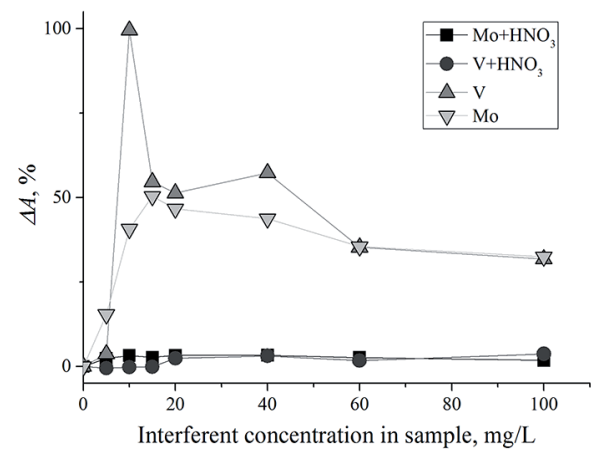

Fig. 4. RAD as a result of interference between bismuth and V, Mo in the presence of nitric acid and without it 


$$
\begin{gathered}
\mathrm{Bi}_{2} \mathrm{MoO}_{6}+4 \mathrm{H}^{+} \leftrightarrows \\
\leftrightarrows \mathrm{MoO}_{4}^{2-}+2 \mathrm{Bi}^{3+}+2 \mathrm{H}_{2} \mathrm{O} \\
\mathrm{BiVO}_{4}+2 \mathrm{H}^{+} \leftrightarrows \mathrm{Bi}^{3+}+\mathrm{VO}_{3}^{-}+\mathrm{H}_{2} \mathrm{O} \\
\mathrm{VO}_{3}^{-}+2 \mathrm{H}^{+} \leftrightarrows \mathrm{VO}_{2}^{+}+\mathrm{H}_{2} \mathrm{O} \\
\mathrm{VO}_{2}^{+}+2 \mathrm{H}^{+} \leftrightarrows \mathrm{VO}^{3+}+\mathrm{H}_{2} \mathrm{O}
\end{gathered}
$$

In the present work, nitric acid was used to avoid precipitation. We showed that addition of small quantities of nitric acid (total concentration in the sample is $0.05 \mathrm{~mol} / \mathrm{L}$ ) eliminates $\mathrm{V}$ - and Mo-related matrix effects, and RAD is not more than $3 \%$ in the range of interferent concentrations from 5 to $100 \mathrm{mg} / \mathrm{L}$.

2. Way of eliminating of matrix effects

In some cases, it is impossible to decrease the acid concentration in the sample or to separate interacting metals that form anions. And in such situations it is convenient to use standard calibration method with calibration blank and standard solutions that include all necessary interferents. However, the use of the standard calibration method is possible only if RAD is relatively constant in the wide range of concentrations of bismuth. In the present work, we showed that RAD is almost concentration-independent in the presence of $\mathrm{HCl}(4.5 \mathrm{~mol} / \mathrm{L}), \mathrm{HNO}_{3}(4.5 \mathrm{~mol} / \mathrm{L})$, $\mathrm{H}_{2} \mathrm{SO}_{4}(4.7 \mathrm{~mol} / \mathrm{L}), \mathrm{V}(20 \mathrm{mg} / \mathrm{L})$ or $\mathrm{Mo}$

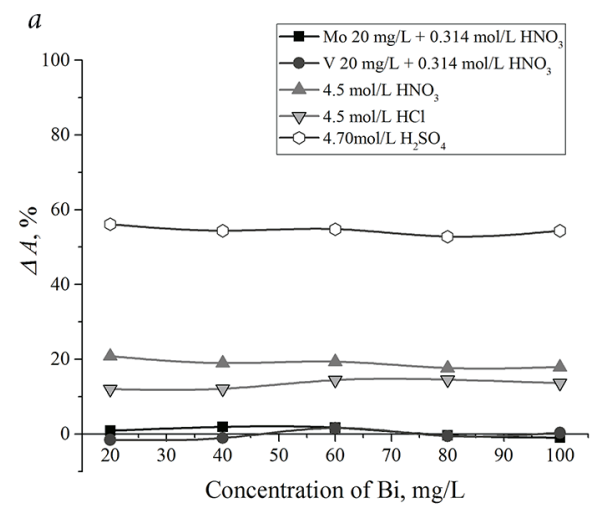

(20 mg/L). As a result, correct calibration curves can be plotted (see Fig. 5).

\section{Optimized parameters and fitting} of calibration curves

Calibration curves were fitted using both linear function and polynomial functions of $2^{\text {nd }}$ and $3^{\text {rd }}$ order in OriginLab software. The strong correlation with linear function was observed in the range of 0-60 mg/L of bismuth for calibration with an ordinary calibration blank. If the calibration blank is a complex mixture, then this concentration range is to be reduced. If the range of concentration of bismuth in standard solutions is wider than 0-60 mg/L, then $2^{\text {nd }}$ or $3^{\text {rd }}$ order polynomial function must be used for fitting, because the linear function gives overestimated values.

The smallest concentration which could be detected by a percent absorption signal of $1 \%$ (0.0044 absorbance units) was accepted as a rough measure of performance known as "sensitivity". It is also known as a characteristic concentration with flame AAS or a characteristic mass with furnace AAS [19]. The characteristic concentration can be measured directly, or obtained by calculation from the calibration curve.

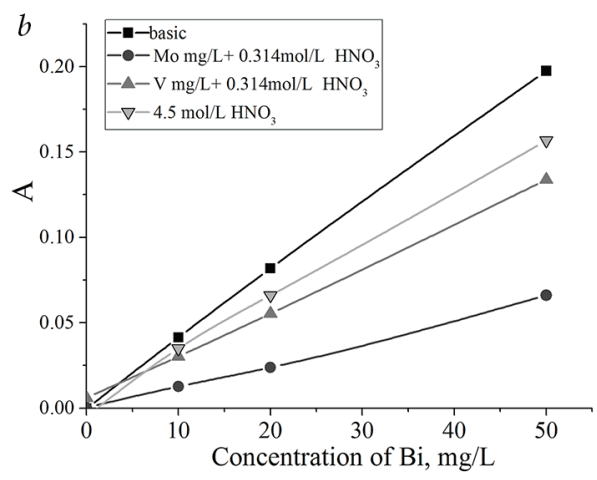

Fig. 5. $a-$ RSD vs consentration of Bi for different interferents; $b$ - Examples of the calibration curves with different calibration blanks 
Instrumental parameters were optimized by finding the maximum values of absorption signal of the senior standard solution and minimization of characteristic concentration. The following parameters were obtained: the lamp current is $75 \%$ of maximum, the time of measurement is $4 \mathrm{sec}$ onds, the burner positioning is $7 \mathrm{~mm}$ high, the fuel consumption (ordinary mixture) is $0.8 \mathrm{~L} / \mathrm{min}$. The characteristic concentration calculated for the linear function range $(0-60 \mathrm{mg} / \mathrm{L}$ of $\mathrm{Bi})$ is $1.24-1.26 \mathrm{mg} / \mathrm{L}$, the characteristic concentration calculated for the polynomial function range $(0-100 \mathrm{mg} / \mathrm{L}$ of $\mathrm{Bi})$ is $1.40-1.46 \mathrm{mg} / \mathrm{L}$. It means that the error margin of the analysis is about $\pm 0.63 \mathrm{mg} / \mathrm{L}$ for the linear function range and about $\pm 0.73 \mathrm{mg} / \mathrm{L}$ for the polynomial function range. No significant difference between fitting by $2^{\text {nd }}$ and $3^{\text {rd }}$ order polynomials was observed.

If an acceptable error of determined concentration of bismuth is $2 \%$ (which, of course, is too much for ordinary chemical analysis, but is acceptable in the case of identification of the complex oxide composition), than the minimal recommended concentration of $\mathrm{Bi}$ in the liquid sample is $31-37 \mathrm{mg} / \mathrm{L}$. The standard additions method requires the concentration of a standard addition to be propor- tional to the concentration of an element in the sample. It means that total concentration of bismuth in the sample exceeds $60 \mathrm{mg} / \mathrm{L}$ and is out of the linear range. Therefore, the traditional way of using linear functions in standard additions method also overestimates the bismuth concentration in the sample, as described below.

4. Determination of Bi content in the real complex oxides

The $\mathrm{Bi}_{1.9} \mathrm{Ba}_{0.1} \mathrm{MoO}_{6}, \mathrm{Bi}_{12.7} \mathrm{Mn}_{0.3} \mathrm{Mo}_{4.6} \mathrm{P}_{0.5} \mathrm{O}_{34}$, $\mathrm{Bi}_{4} \mathrm{~V}_{0.4} \mathrm{Ta}_{1.6} \mathrm{O}_{11}, \mathrm{Bi}_{4} \mathrm{~V}_{1.5} \mathrm{Cr}_{0.4} \mathrm{Fe}_{0.1} \mathrm{O}_{11}$ complex oxides were weighted and dissolved in acids. The sample masses were within certain ranges so as to make the concentration of bismuth of 30-40 mg/L in the final solutions. The obtained samples were analyzed by standard additions method, the concentrations of additions were 20, 40 and $60 \mathrm{mg} / \mathrm{L}$. Linear and $2^{\text {nd }}$ order polynomial functions were used for fitting the standard addition curve. To check the correctness of the method, the second series of samples was prepared with a control addition (CA) of $10 \mathrm{mg} / \mathrm{L}$ of bismuth. Concentrations of bismuth were determined in it in the same way. The difference between the series with the control addition and that without it was denoted as "measured control addition" (MAD). The closer MAD is to $10 \mathrm{ppm}$, the more correct the method is.

Table 1

Measured concentrations of bismuth in the sample and MAD values in the cases of using different equations for the standard addition curve fitting

\begin{tabular}{c|c|c|c|c}
\hline $\begin{array}{c}\text { Type of the standard } \\
\text { addition curve }\end{array}$ & \multicolumn{2}{|c|}{ Linear function } & \multicolumn{2}{c}{$2^{\text {nd }}$ order polynomial function } \\
\hline Sample & $\begin{array}{c}\text { Concentration } \\
\text { of Bi in the sample }\end{array}$ & MAD & $\begin{array}{c}\text { Concentration } \\
\text { of Bi in the sample }\end{array}$ & MAD \\
\hline $\mathrm{Bi}_{1.9} \mathrm{Ba}_{0.1} \mathrm{MoO}_{6}$ & $44.24 \pm 0.63$ & $12.28 \pm 0.63$ & $40.86 \pm 0.73$ & $10.05 \pm 0.73$ \\
\hline $\mathrm{Bi}_{12.7} \mathrm{Mn}_{0.3} \mathrm{Mo}_{4.6} \mathrm{P}_{0.5} \mathrm{O}_{34}$ & $44.04 \pm 0.63$ & $11.06 \pm 0.63$ & $40.47 \pm 0.73$ & $10.44 \pm 0.73$ \\
\hline $\mathrm{Bi}_{4} \mathrm{~V}_{0.4} \mathrm{Ta}_{1.6} \mathrm{O}_{11}^{*}$ & $35.43 \pm 0.63$ & $11.91 \pm 0.63$ & $33.34 \pm 0.73$ & $10.35 \pm 0.73$ \\
\hline $\mathrm{Bi}_{4} \mathrm{~V}_{1.5} \mathrm{Cr}_{0.4} \mathrm{Fe}_{0.1} \mathrm{O}_{11}$ & $46.42 \pm 0.63$ & $11.70 \pm 0.63$ & $42.13 \pm 0.73$ & $10.31 \pm 0.73$ \\
\hline
\end{tabular}

${ }^{*}$ sample contained precipitate (filtered) 
The results are given in Table 1 . It can been seen that the measured concentrations, obtained by linear fitting of the curves, overestimate MAD and bismuth concentration in the sample. In opposite, MAD determined with the $2^{\text {nd }}$ order polynomial function is close to the theoretical one. It clearly shows that using polynomial function gives more accurate values for standard additions method for determination of bismuth by acetylene/air AAS.

The calibration curve method was also tested for determination of bismuth in complex oxides under investigation. These oxides contain interfering elements (Mo, V) and, therefore, an addition of acid was required. However, the complex oxides were dissolved in concentrated acids, so no additional acid was necessary. The concentration of bismuth in the senior standard was $60 \mathrm{mg} / \mathrm{L}$, and the linear fitting function was used. To check the correctness of the method, the second series of samples was prepared with a control addition (CA) of $10 \mathrm{mg} / \mathrm{L}$ of bismuth, and, as for the standard additions method, the MAD values were determined. It was shown that
MAD is determined correctly and the concentration of bismuth in the samples is consistent with the results obtained by method of standard additions (see Table 2). Thus, in the case of complex oxides with low concentrations of interferents, the matrix effects can be eliminated by adding acids only, as was observed for the model solutions in the interference studies described above.

However, the concentration of interfents $(\mathrm{Mo}, \mathrm{V})$ in the samples was low $(<10 \mathrm{mg} / \mathrm{L})$, so we introduced additional $20 \mathrm{mg} / \mathrm{L}$ of interferents and $0.05 \mathrm{~mol} / \mathrm{L}$ of nitric acid to observe the interferential effects. In the model solutions, only bismuth and interferent metals were present, and the matrix effects were eliminated successfully by acids only. But the real sample constitutes more complex mixture and, as a result of the matrix effects, we observed underestimated analysis results (see the last column in Table 2). Hence, the calibration curve method is correct only at low $(<10 \mathrm{mg} / \mathrm{L})$ concentrations of interferents.

Measured concentration of $\mathrm{Bi}$ in the sample

Table 2

and MAD values in the case of using the calibration curve method

\begin{tabular}{c|c|c|c}
\hline Sample & $\begin{array}{c}\text { Concentration } \\
\text { of Bi in the sample }\end{array}$ & MAD & $\begin{array}{c}\text { Concentration of Bi } \\
\text { in the sample with additional } \\
\text { interferent }\end{array}$ \\
\hline $\mathrm{Bi}_{1.9} \mathrm{Ba}_{0.1} \mathrm{MoO}_{6}$ & $40.86 \pm 0.65$ & $10.16 \pm 0.65$ & $40.55 \pm 0.65$ \\
\hline $\mathrm{Bi}_{12.7} \mathrm{Mn}_{0.3} \mathrm{Mo}_{4.6} \mathrm{P}_{0.5} \mathrm{O}_{34}$ & $40.99 \pm 0.65$ & $9.84 \pm 0.65$ & $40.69 \pm 0.65$ \\
\hline $\mathrm{Bi}_{4} \mathrm{~V}_{0.4} \mathrm{Ta}_{1.6} \mathrm{O}_{11}^{*}$ & $33.24 \pm 0.65$ & $9.84 \pm 0.65$ & $30.78 \pm 0.65$ \\
\hline $\mathrm{Bi}_{4} \mathrm{~V}_{1.5} \mathrm{Cr}_{0.4} \mathrm{Fe}_{0.1} \mathrm{O}_{11}$ & $42.00 \pm 0.65$ & $9.46 \pm 0.65$ & $38.54 \pm 0.65$ \\
\hline
\end{tabular}

* the sample contained precipitate (filtered)

\section{Conclusions}

In the present work, the air/acetylene flame atomic absorption spectrometry was shown to be acceptable for bismuth determination in complex oxides. Interference studies demonstrated that vanadium and molybdenum affect the absorbance. 
It was shown that fitting with polynomial function is more appropriate for standard additions method for determination of bismuth by acetylene/air flame atomic absorption spectrometry. The calibration curve method was shown to be correct only at low $(<10 \mathrm{mg} / \mathrm{L})$ concentration of interferents; at higher concentrations the standard additions method must be used.

\section{Acknowledgements}

The work was financially supported by Russian Foundation for Basic Research, project № 18-33-00921.

\section{References}

1. Cross LE, Pohanka RC. Ferroelectricity in bismuth oxide type layer structure compounds. Mat Res Bull. 1971;6(10):939-949.

DOI:10.1016/0025-5408(71)90072-9

2. Malathi A, Madhavan J, Ashokkumar M, Arunachalam P. A review on $\mathrm{BiVO}_{4}$ photocatalyst: Activity enhancement methods for solar photocatalytic applications. Appl Catal A. 2018;555:47-74.

DOI:10.1016/j.apcata.2018.02.010

3. Emelyanova YV, Mikhailovskaya ZA., Buyanova ES, Petrova SA. Synthesis, structure, and properties of substituted bismuth niobates $\mathrm{Bi}_{3} \mathrm{Nb}_{1-\mathrm{x}} \mathrm{Er}_{\mathrm{x}} \mathrm{O}_{7-\mathrm{d}}$. Rus J Appl Chem. 2017;90(3):354-360.

DOI:10.1134/S1070427217030053

4. Vannier RN, Pernot E, Anne M, Isnard O, Nowogrocki G, Mairesse G. $\mathrm{Bi}_{4} \mathrm{~V}_{2} \mathrm{O}_{11}$ polymorph crystal structures related to their electrical properties. Solid State Ionics. 2003;157(1):147-153.

DOI:10.1016/S0167-2738(02)00202-3

5. Kaur G, Pandey, OP, Singh K. Optical, structural, and mechanical properties of different valence-cation-doped bismuth vanadate oxides. Physica Status Solidi A. 2012;209(7):1231-1238.

DOI:10.1002/pssa.201127636

6. Wang J, Neaton B, Zheng H, Nagarajan V, Ogale SB, Liu B, Viehland D, Vaithyanathan V, Schlom, DG, Waghmare, UV, Spaldin NA, Rabe KM, Wuttig,M, Ramesh R. Epitaxial $\mathrm{BiFeO}_{3}$ multiferroic thin film heterostructures. Science. 2003;299(5613):17191722.

DOI:10.1126/science.1080615.PMID 12637741.

7. $\mathrm{Fu} \mathrm{S}$, Ozoe H. Growth of $\mathrm{Bi}_{12} \mathrm{GeO}_{20}$ crystal rods and fibers by the improved floating zone method. J Mater Sci. 1999;34 (2):283-290.

DOI:10.1023/A:1004430311364.

8. Shen C, Zhang H, ZhangY, Xu H, Yu H, Wang J, Zhang S. Orientation and temperature dependence of piezoelectric properties for sillenite-type $\mathrm{Bi}_{12} \mathrm{TiO}_{20}$ and $\mathrm{Bi}_{12} \mathrm{SiO}_{20}$ single crystals. Crystals. 2014;4(2):141-151.

DOI:10.3390/cryst 4020141 
9. Das AK, Chakraborty R, Cervera ML., de la Guardia M. Analytical techniques for the determination of bismuth in solid environmental samples. Trends Anal Chem. 2006;25(6):599-608.

DOI:10.1016/j.trac.2006.01.006

10. Codony F, Domenico P, Mas J. Assessment of bismuth thiols and conventional disinfectants on drinking water biofilms. J Appl Microbiol. 2003;95(2):288-93.

DOI:10.1046/j.1365-2672.2003.01974.x

11. Madrakian T, Afkhami A, Esmaeili A. Spectrophotometric determination of bismuth in water samples after preconcentration of its thiourea-bromide ternary complex on activated carbon. Talanta. 2003;60(4):831-8.

DOI:10.1016/S0039-9140(03)00135-8

12. Pournaghi-Azar MH., Hossein M, Bahar S. Selective determination of trace-bismuth by extraction-differential pulse polarography in non-aqueous media. [Internet]. Iran J Chem Chem Eng. 2001;20(2):59-65. Available from: http://www.ijcce.ac.ir/ article_9971_d79d426fa1a46f24492b40f4a3cc28d2.pdf

13. Şahan S, Saçmacı S, Şahin U., Ülgen A., Kartal S. An on-line preconcentration/ separation system for the determination of bismuth in environmental samples by FAAS, Talanta. 2010;80(5):2127-2131.

DOI:10.1016/j.talanta.2009.11.019

14. Afkhami A, Madrakian T, Siampour H. Cloud point extraction spectrophotometric determination of trace quantities of bismuth in urine. J Braz Chem Soc. 2006;17(4):797-802.

DOI:10.1590/S0103-50532006000400024

15. Kilinc E, Bakirdere S, Aydin F, Ataman YO. Sensitive determination of bismuth by flame atomic absorption spectrometry using atom trapping in a slotted quartz tube and revolatilization with organic solvent pulse. Spectrochim Acta Part B. 2012;7:84-88.

DOI:10.1016/j.sab.2012.06.004

16. Dedina J, Tsalev DL. Hydride Generation Atomic Absorption Spectrometry. Chicester: Wiley \& Sons; 1995. 544 p.

17. Dobrowolski R, Dobrzynska J, Gawronska B. Determination of bismuth in environmental samples by slurry sampling graphite furnace atomic absorption spectrometry using combined chemical modifiers. Environ Monit Assess. 2015;187(4125):1-8.

DOI:10.1007/s10661-014-4125-7

18. SOLAAR CookBook. Recommendations for Atomic Absorbtion Determination of Elements. ThermoFisher Scientific; 2007.

19. Cookies on PerkinElmer: White papers. Sensitivity, Background, Noise and Calibration In Atomic Spectroscopy — Effects on Accuracy and Detection Limits. [Internet]. Available from: https://www.perkinelmer.com/lab-solutions/resources/docs/WHP Atomic_Spectroscopy-Effects_on_Accuracy_and_Detection_Limits_013559_01.pdf 